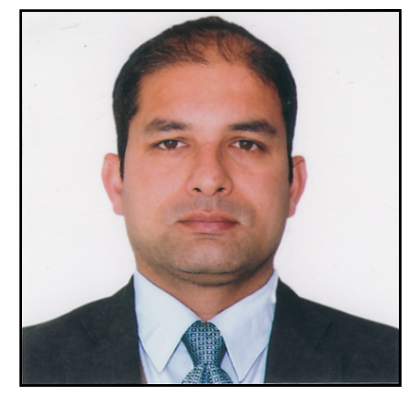

\title{
Practice of Good Scientific Writing
}

Dr Dipendra Raj Pandeya

International Editor

Our science and scientific explorations are integral components in the process of research and development. Therefore, keeping abreast of recent scientific knowledge and development is an imperative process of a professional scientist. Scientific literature such as publications are among the most popular ways to update and up-skill one's knowledge in a particular area. One can either become a consumer of scientific publication as a reader or s/he could also contribute to the body of literature through academic publications in quality peer-reviewed journals.

Having contributed to academic writing as an author is like your passport to your scientific community, not only to share your knowledge but also to gain professional recognition. Your contribution to publication also helps disseminate your new and foremost findings or techniques among scientific and academic communities. In order to be an accomplished scientist, one needs to have good scientific writing skills and be able to express the scientific knowledge effectively and efficiently to the scientific/academic community.

Before you start writing, it is important that you should be aware of the main goals of your publication. Your research should answer the relevant questions of the involved field and should arouse interest in the readers. Furthermore, the researcher should also know whether the research and findings of the work are publishable at the given point or not. If the answers are ticked off positively, then the researcher can start preparing the manuscript.

Most research papers are based upon the IMRaD format. The word IMRaD stands for the initial letters of the words Introduction (I), Methods (M), Results (R), and Discussion (D). The Introduction describes the scope and purpose of the research in the light of recent information on the existing research; the Methods explain how the analysis was done; the Results section reports your audience to know what the investigation showed; and the Discussion section should explain the significance of the new information provided by your study and suggestions for future studies. The IMRaD structure has been followed by a progressively increasing

DOI: http://dx.doi.org/10.3126/mjsbh.v17i1.19544

Submitted on: 2018-04-01

Accepted on: 2018-04-02

This work is licensed under: http://creativecommons.org/licenses/bync-nd/4.0/ (c) 2018 Medical Journal of Shree Birendra Hospital 
number of academic journals and has been the basis for most researches. It is a very effective approach as it facilitates the literature review and lets the readers understand the research more logically.

Good scientific writing with the methodical approach is not the only criteria for getting published in scientific journals. For publishing in a particular journal, it's very important to follow the author guidelines. Every journal has a particular format of writing and it is expected that the particular journal is going to publish the articles in the same particular format. This is very important for the journal to be consistent in all the publications.

In addition, writing a good research article can seem challenging at first, however, if a researcher plans it properly, the challenge becomes interesting. Your research may conclude with meaningful answers to the unanswered questions in a particular scientific field and serve as a stimulus for further studies in the future. Well-written papers get published more frequently and can easily attract the attention of the readers. They are highly read, recommended as well as cited. Reviewers are more willing to review a well written research article and give favourable comments to improve the quality of the study. The authors should make every effort to implement the proper use of correct grammar. Poor language quality, including errors in grammar, spelling mistakes, typographical errors could delay the publication or lead to outright rejection of the paper.

Ultimately, the readers of your scientific manuscript are your primary examiners. They are going to examine the details of all the appropriate components of your study: purpose, background and rationale, strategies, results, discussion and conclusions. The elements of good scientific publishing must certainly be clear, precise, and logical. Finally, scientific work is incomplete until the results are disseminated to the larger community. Thus, effective scientific writing will create information exchange, to improve knowledge progress, ideas and improve your colleague's future work.

Dr Dipendra Raj Pandeya

Department of Clinical Laboratory Science, College of Applied Medical Sciences, Al Jouf University, Saudi Arabia email: dipendra.pandey@gmail.com 